\title{
NOTE ON MODEL STUDIES OF FOLDING OF MORAINES IN PIEDMONT GLACIERS
}

\author{
By Hans Ramberg \\ (Institute of Mineralogy and Geology, University of Uppsala, Uppsala, Sweden)
}

ABstract. The pattern of flow of moraine-carrying glaciers is studied by models whirled in a centrifuge. Because of the rather high centrifugal force ( $1,000 \mathrm{~g})$, substances with high viscosity, such as bouncing putty and stitching wax (viscosity around $10^{6}-10^{7}$ poises), can be used as glacier-imitation materials. As moraineimitation material powdered hard wax is used. The strength and high viscosity of the model materials permit detailed structures to be studied without the disturbing effects of sagging after being run to the chosen stage in the centrifuge. Stroboscopic light makes it possible to follow the evolution of the flow and to stop the centrifuge and thus the flow at any stage.

Rather realistic-looking fold structures of the kind seen in some piedmont ice sheets develop readily after a few minutes' run in the centrifuge.

The mechanism of fold evolution is discussed.

No slip (or shear) has taken place along a "foliation" which sometimes develops parallel to the axial planes of the folds.

RÉsumé. On étudie l'allure de l'écoulement d'un glacier qui transporte de la moraine au moyen de modèles que l'on fait tourner dans une centrifugeuse. Par suite des forces centrifuges assez grandes ( 1 ooo $g$ ), on peut utiliser comme matériaux de reproduction du glacier des substances dont la viscosité est élevée telles que le mastic élastique et la cire à suturer dont la viscosité est de l'ordre de $10^{6} a^{4} 10^{7}$ poises. On se sert d'une cire dure en poudre pour reproduire la moraine. La résistance à la rupture et la grande viscosité des matériaux du modèle permettent d'observer des structures détaillées sans perturbation disproportionnée lorsqu'on atteint l'étape désirée de la centrifugation. Un éclairage stroboscopique permet de suivre l'évolution de l'écoulement et d'arrêter la centrifugation et par conséquent l'écoulement, à n'importe quel moment. Des structures de plissement assez réalistes telles que celles que l'on voit dans certaines langues de glace de piedmont se développent facilement après quelques minutes de passage dans la centrifugeuse. On discute le
mécanisme de l'évolution des plissements. Aucun glissement (ni cisaillement) ne s'est manifesté le long des "foliations" qui se développent de
temps en temps parallèlement aux plans axiaux de plissement.

Zusammenfassung. Die Fliessvorgänge in moränenerfüllten Gletschern werden an Modellen untersucht, die in einer Zentrifuge geschleudert wurden. Infolge der ausserordentlich hohen Zentrifugalkraft (Iooo $g$ )

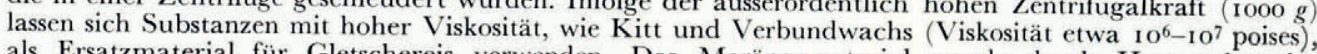
als Ersatzmaterial für Gletschereis verwenden. Das Moränenmaterial wurde durch Hartwachspuder nachgeahmt. Die Festigkeit und hohe Viskosität der Modellsubstanzen erlauben das Studium detaillierter Strukturen ohne Störung der Durchbiegung, nachdem das gewünschte Stadium in der Zentrifuge erzeugt wurde. Stroboskopisches Licht ermöglicht die Beobachtung des Fliessvorganges, der durch Abschalten der Zentrifuge in jedem Stadium unterbrochen werden kann.

Nach wenigen Minuten entwickeln sich in der Zentrifuge sehr naturgetreue Faltenstrukturen von der Art, wie sie in einigen Eisloben zu finden sind.

Der Mechanismus der Faltenbildung wird diskutiert.

Entlang einer "Bänderung", die gelegentlich parallel zu den Achsenebenen der Falten auftritt, findet kein Gleiten oder Scheren statt.

DURING experimental studies of gravity tectonics (Ramberg, I963[a]) by means of models whirled in a large-capacity centrifuge (Fig. IA), a few structures simulating the complex folding of moraines and debris bands in piedmont glaciers were tested qualitatively.

As the mechanism of evolution of these fold structures, and perhaps also the technique applied, may be of interest to glaciologists, a brief report is considered worthwhile despite the preliminary nature of the tests.

The driving agency of an active glacier is almost solely the difference in potential energy between different points in the ice body, inasmuch as the movement is so slow that the inertial terms in the fluid-dynamic equations become insignificant.

The potential energy per mol volume is defined thus

$$
\Delta \Phi=V \Delta P+\rho g V \Delta h,
$$

where $\Delta P$ is the pressure difference between the point in question and a fixed point of reference; $V$ is the mol volume of the incompressible material; $\rho$ is density; $g$ is acceleration due to gravity; and $\Delta h$ is difference in vertical distance between the point in question and the point of reference. 


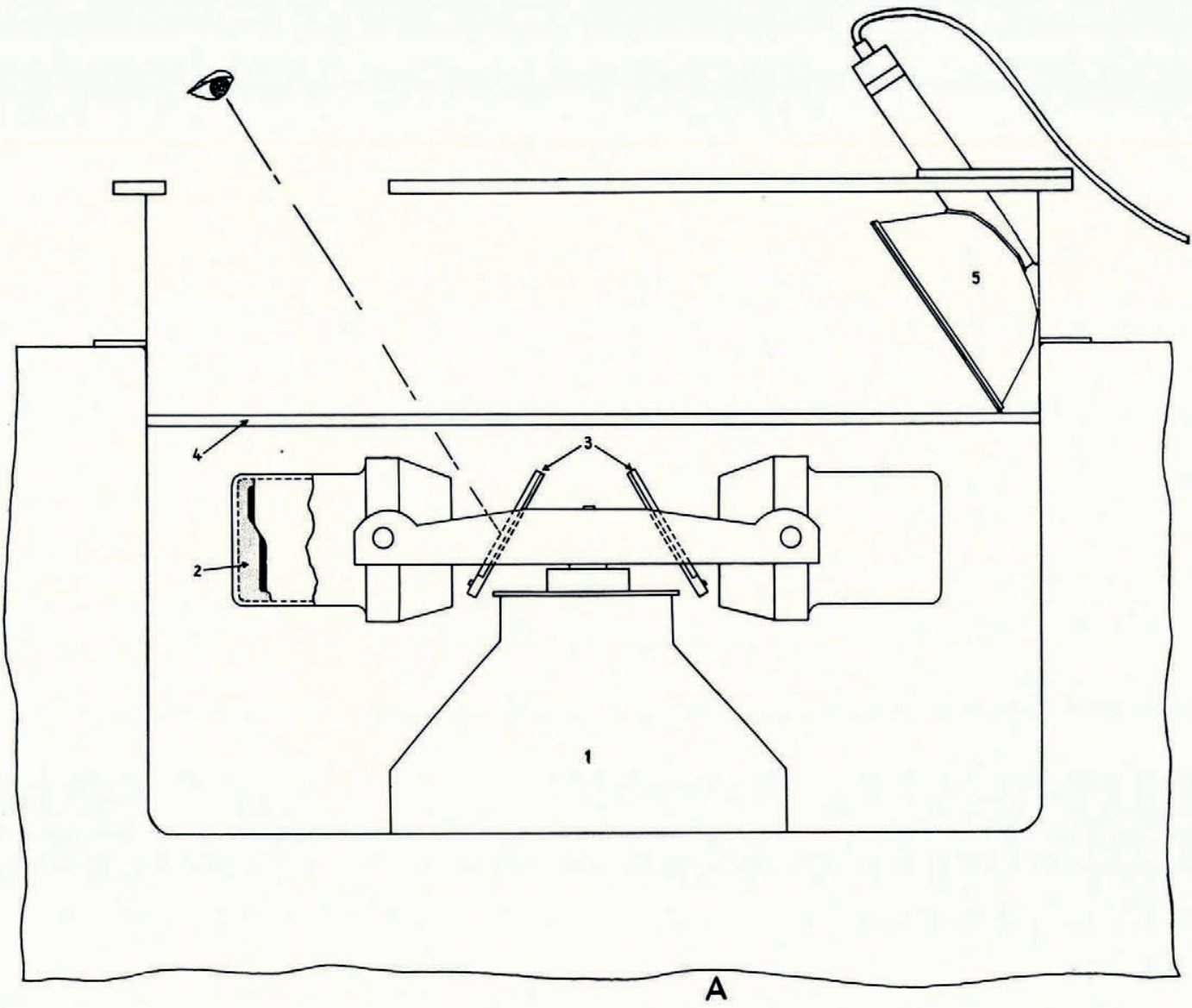

Fig. IA. Section through the centrifuge bowl showing the position of the model during runs. (I) Motor; (2) model shown in section through the trunnion cup; (3) mirrors; (4) plexiglass cover; (5) electronic stroboscopic light. Diameter of centrifuge bowl is $62 \mathrm{~cm}$.

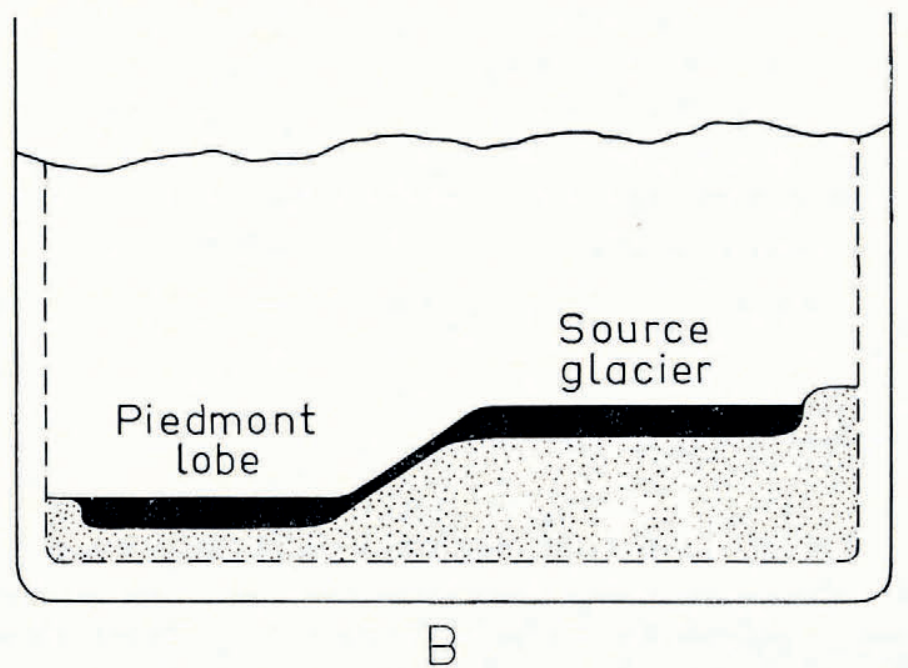

Fig. IB. Separate section through the model with source glacier and piedmont lobe. Length of section is $10 \mathrm{~cm}$. 
If a given model of a glacier is whirled in a centrifuge the acceleration due to gravity, $g$, is replaced by the centripetal acceleration, $a$, which may be made several thousand times greater than $g$. Since the pressure at any given point in a centrifuged model is proportional to the acceleration (the hydrostatic pressure is, for example, $P=\rho a D$, where $D$ is depth from the free surface to the point in question), it follows that the driving potential difference, $\Delta \Phi$, between any two given points in the model is directly proportional to the centripetal acceleration, provided the substance is incompressible. It is obvious then that the centrifuge technique offers great advantages for scale-model studies of the evolution of complicated flow patterns in moraine-charged glaciers.

One advantage of the centrifuge technique, as compared with models at rest in the field of gravity, is that strong and highly viscous visco-elastic materials can be used for glacier imitation. Yet, the mature structure will develop in the course of but a few minutes in centrifuged models. Because of the relatively great strength of the imitation materials and/or their high viscosity (e.g. $10^{5}-10^{8}$ poises), the rate of flow is zero or very small as long as the models are not whirled in a centrifuge. Hence the initial stage of a model (Fig. IB) can be constructed without the disturbing effect of sagging such as would occur in imitation substances soft enough to permit maturing of models at rest in the field of gravity. Likewise, after the mature structure has developed in the centrifuged model the pattern may be studied in great detail by, for example, sectioning under the microscope without further appreciable deformation occurring during the inspection.

Application of stroboscopic light (Fig. IA) permits observation of the evolution of the flow pattern during the run in the centrifuge.

The simple tests described below were not aimed at obtaining information on the microscopic mechanism of crystalline flow or development of fabric of glacier ice. Neither were the tests so arranged as to permit studies of fracturing during ice flow. The purpose was to follow the evolution of fold patterns in moraine-charged piedmont glaciers such as the Malaspina Glacier in Alaska (Sharp, I 958).

The substances used for ice imitation, viz. various types of bouncing putty, ${ }^{*}$ were therefore not crystalline but behaved like very viscous liquids. Bouncing putty fractures in tension under deviatoric stresses greater than a certain low limit, but the stresses developed in the centrifuged models were not sufficient to cause fracturing.

Three grades of bouncing putty with somewhat unlike viscosities were used as glacierimitation materials, viz. Dow Corning Nos. C-455 I, XC-2-0950 and XC-2-095I. Nos. C-455 I and $\mathrm{XC}-2-0950$ are relatively soft with a viscosity of the order $10^{5}-10^{6}$ poises under the conditions of the runs, but No. XC-2-095 I is somewhat harder and more viscous.

As imitation material for moraines and debris, powdered hard black Apiezon wax was used. The powdered wax was mixed with bouncing putty to yield a heterogeneous mixture that was stiffer and considerably more viscous than pure bouncing putty. Strips of this mixture were embedded as moraines in the model glaciers of pure bouncing putty.

As a substratum for the glacier a mountainous landscape was constructed from wax rigid enough not to sag under the centrifugal force. The whole model fitted in a centrifuge cup with a diameter of $10.5 \mathrm{~cm}$.

The essential parts of the landscape were an intramontane basin in which the source of ice-imitation material was to be placed, a channel leading down from the intramontane basin, and a flat piedmont basin in which the descending model glacier could spread out (Figs. 2 and 3). The difference in height between the intramontane basin and the piedmont flat would be about I cm. (Fig. IB).

Before centrifuging the models, the intramontane basin was filled with a flat cake of bouncing putty in which strips of the moraine materials described above were embedded. In

* The writer is obliged to Mr. W. F. Morgan of the Dow Corning Company for supplying liberal samples of the bouncing putty. 


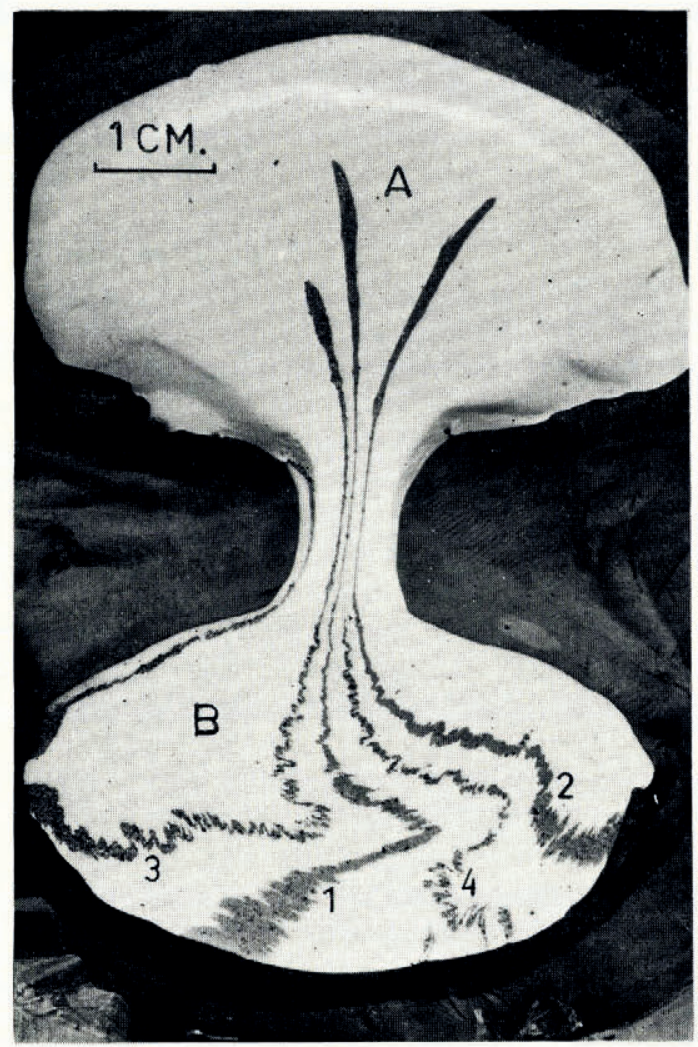

Fig. 2. Centrifuged model of a bouncing putty glacier (white, Dow Corning No. XC-2-095o) with enclosed moraines (of powdered wax) that have been stretched in the narrow part of the glacier, and folded in the spread piedmont lobe. The source "ice" cap $(A)$ is about I cm. "higher" than the piedmont lobe. ("Higher" means closer to the axis of the centrifuge rotor during the run.) Moraines $I$ and 2 contain less powdered wax and are therefore less competent than moraines 3 and 4 . Note the different style of folding (see also Figure 6 ) between the two kinds of moraines

order to study how the style of deformation of the moraines in the descending glacier and in the piedmont lobe might depend upon the rheological contrast between imitation ice and moraine, strips of rather stiff stitching wax and of bouncing putty with different shades of colour and somewhat unlike viscosities were also embedded in the pure imitation ice in some tests.

The models so constructed were then run at $\mathrm{I}, \mathrm{OoO} \mathrm{g}$ in a centrifuge and the evolution of the flow pattern was studied by stroboscopic light and photographed. Under a strong centrifugal force the moraine-charged model glacier would creep down the channel and spread slowly out on the piedmont flat.

After the material had spread over a considerable part of the piedmont flat, the rate of flow in the channel and in the piedmont sheet close to the channel would be approximately steady and not affected by the erratic drag in the frontal part of the lobe which spread radially out on the flat. The description below refers to this approximate condition of steady-state flow.

Under this condition of flow the moraines in the channel were always parallel to the axis of the channel, showing a high degree of compression normal to the channel compared with the parts of the same moraines that remained in the intramontane basin (Figs. 2 and 3). In most runs the moraines were affected by folding at the outlet of the channel, the folding generally increasing in intensity (i.e. increasing amplitude but decreasing wave-length of a given set of folds) as they moved out on to the piedmont sheet (see Figs. 2, 4, 5, 7 and 8). The fold pattern thus developed in the models is very similar to that displayed by the type example of a 


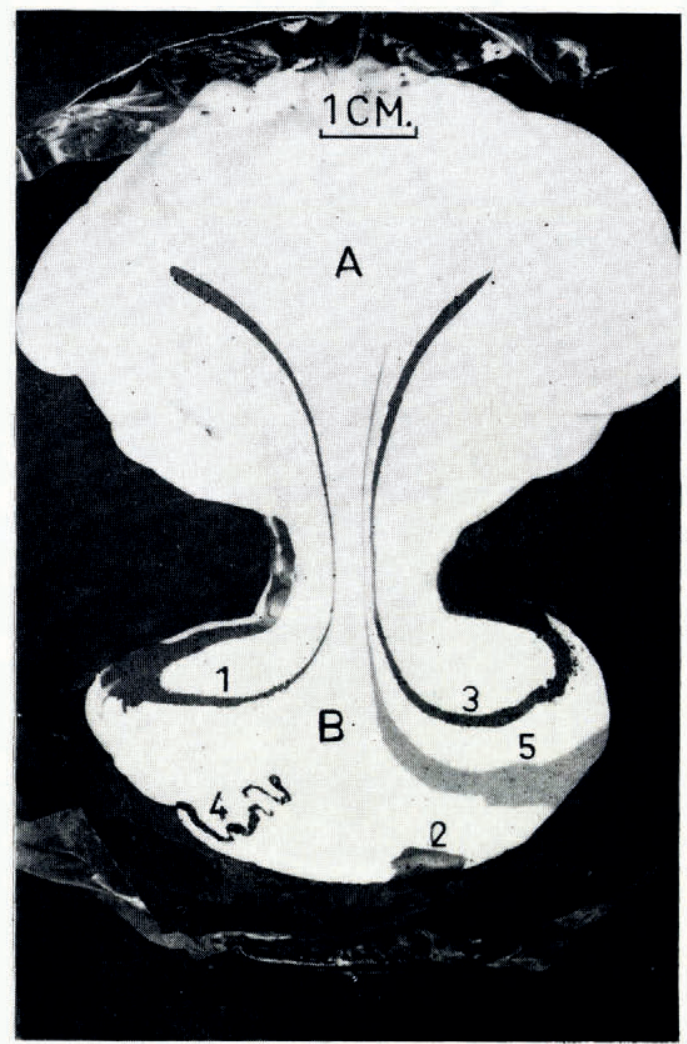

Fig. 3. Centrifuged model of a bouncing putty glacier (white, Dow Corning No. XC-2-095I) with three moraines containing a moderate amount of powdered wax $(I, 2,3)$, a fourth containing much powdered wax (4) and a fifth containing almost no powdered wax (5). The white bouncing putty in this model is considerably more viscous or stiff than that used in the model in Figure 2 (see p. 2Io). Only moraine (4), which contains much powdered wax, is significantly stiffer than the enclosing putty and therefore buckles. The light grey moraine $(5)$ is soft enough to reflect passively the strain of the embedding substance. The variation in width of moraine (5) is therefore a measure of the extension strain normal to the moraine which increases toward the periphery of the piedmont lobe. Inasmuch as the thickness of the lobe is reasonably constant, it follows that the compressive strain parallel to the moraine also increases in magnitude toward the periphery of the lobe. The source "ice" cap A is about $I \mathrm{~cm}$. higher than the piedmont sheet $B$ when placed in the centrifuge

piedmont glacier, viz. the Malaspina Glacier in south Alaska (Sharp, I958). Figures Io and I I show some features of the Malaspina Glacier.

Studies of the behaviour of embedded strips of materials with unlike viscosity and/or rigidity show that one may distinguish three different causes of the folding: (I) buckling in response to layer-parallel compression of competent layers embedded in less competent media; (2) bending of enclosed sheet-shaped bodies that passively mimic the heterogeneous strain in the region, and (3) accentuation of amplitude and compression of wave-length of an original curved pattern in a field of homogeneous strain.

(I) When the embedded strips consist of the above-described materials that are more competent, i.e. more viscous and/or more rigid than the surrounding model ice, buckling starts within the region where the flow passes from the channel to the piedmont sheet (Figs. 2 and 5). The reason for this is simple: on the piedmont flat outside the outlet of the channel the model glacier undergoes compression in a direction parallel to the moraines (and a corresponding extension normal to the embedded moraines). Theory and experiments (Biot, r $96 \mathbf{r}$; Ramberg, I963 [b]) show that enclosed relatively competent sheets that are parallel to compressive strain generally tend to buckle. 


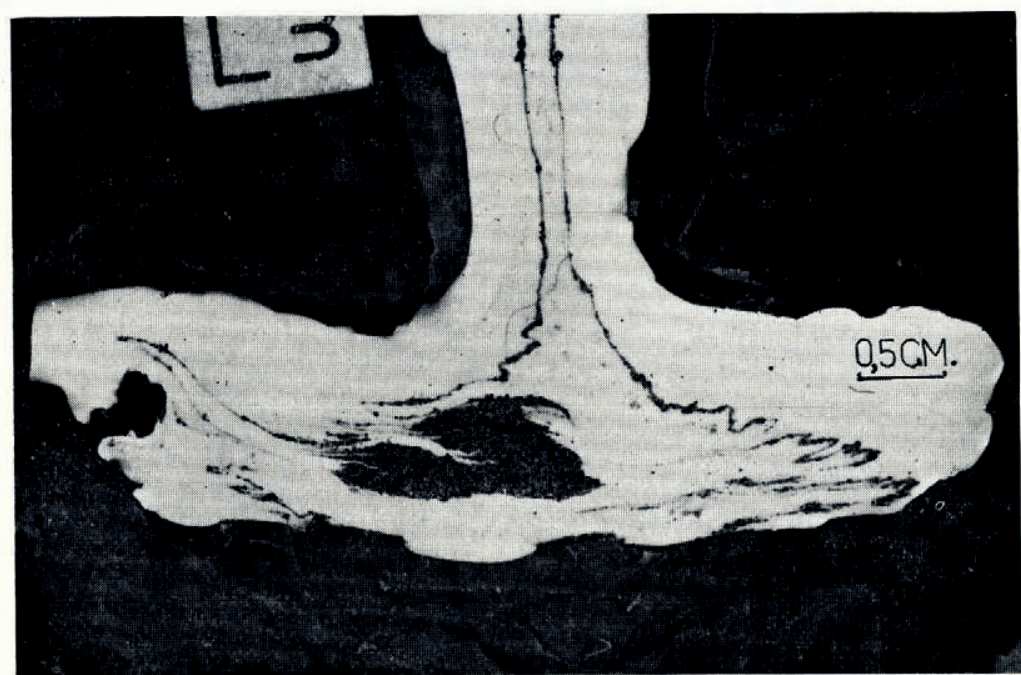

Fig. 4. Buckled and otherwise folded powdered-wax moraines in the piedmont lobe of a glacier model of bouncing putty (white, Dow Corning No. XC-2-095o) run in a centrifuge

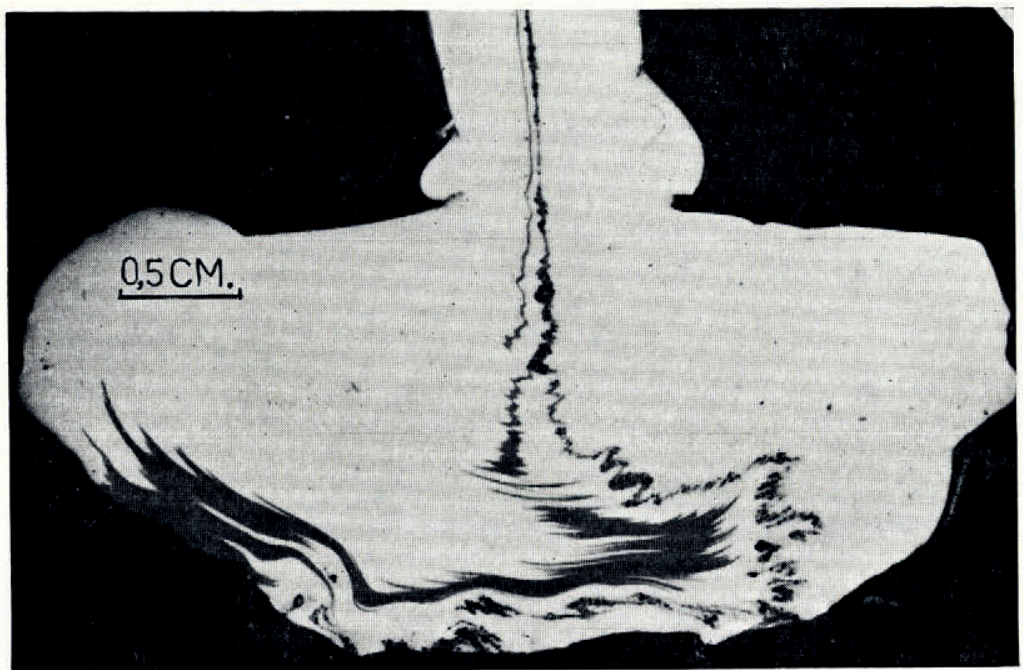

Fig. 5. The granular band in the piedmont lobe of white bouncing putty is powdered-wax moraine that has been buckled during flow under a centrifugal force. The dark even-coloured chevron-folded band consists of brown bouncing putty whose folding is partly a passive reflection of the contact strain adjacent to the buckled layer, partly an accentuation of the curves in the field of simple affine compressive strain along the radius of the lobe (see text and Figure 13)

The imitation-moraine material of bouncing putty mixed with powdered wax is more viscous and stiffer than pure bouncing putty, the contrast in rheological properties increasing with increasing amount of admixed powdered wax. Consequently, the imitation moraines start to buckle in the region where the channel glacier joins the piedmont sheet, the detailed style of the buckles depending upon the relative rigidity of the morainic material, i.e. the concentration and grain-size of admixed powdered wax (see Figs. 6 and 7). That natural moraines buckle when exposed to compression parallel to their length is strikingly displayed by the Susitna Glacier in Alaska as shown in Figure I2 (Sharp, 1948).

(The buckling phenomenon may also be demonstrated by enclosed strips of stitching wax which is considerably more viscous than the enclosing bouncing putty (see Fig. 8).) 


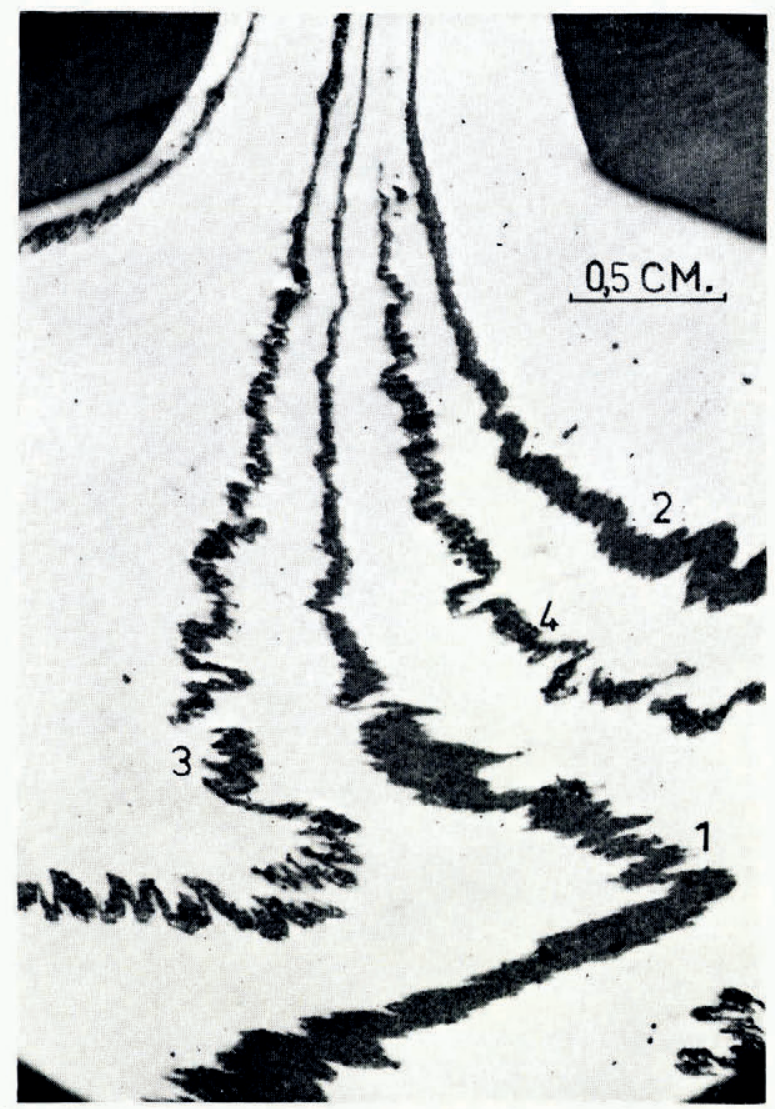

Fig. 6. Detail of the folded moraines in Figure 2 at a later stage of development. Note concentrically arranged surface ripples whose axes are parallel to the axial planes of the folds in the moraines. The jagged outline of the folds, particularly of those in the least competent moraines ( $I$ and 2 ), is exactly of the kind assumed to be caused by slip parallel to the axial planes in rocks and glaciers. In the models, however, the jagged outline of the folded layers is simply a geometric effect of the comfressive strain normal to the axial plane and the extension strain parallel to that plane (see Figure I 3 ). Therefore, the more competent the folded layer, the more rounded and less jagged and pointed the folds; compare different types of folded layers in Figures 5,7 and 8

(2) The deformation of a flowing body may be non-affine and contorted (heterogeneous strain) for various reasons other than buckling such as drag along the bottom and sides, or because of varying slope and other irregularities on the surface of the substratum. Within the region of contact strain adjacent to competent inclusions in a flowing body, such as a buckling moraine in a glacier, the deformation of the enclosing homogeneous body is also heterogeneous.

Under such conditions originally straight linear or planar structures, even if rheologically indistinguishable from the surrounding material, become curved and may display folded patterns. Whereas true buckle folds show a certain relationship between wave-length and thickness of a competent layer of a given material, no such relationship is to be expected for the fold pattern of layers that mimic passively the non-affine flow of the surrounding body.* Such folds due to non-affine flow, often with erratically varying wave-length, may be superimposed on buckle folds such as shown in Figures 2 and 5 .

(3) Independent of the reason for the curvature of originally linear or planar structures, whether formed by active buckling or by passive mimicking of the non-affine flow, additional

* The contact strain on either side of a competent buckling layer reflects passively the relatively regular pattern of the buckles. Folds which mimic passively the periodically varying non-affine strain in the contact zone tend, of course. to be as regular as the buckle folds themselves (see Fig. 5 !. 
strain, even if homogeneous, will accentuate the wavy pattern, provided the added strain has a compressional component normal to the axial plane of the folds. The stronger the compressive strain, the greater is the increment in amplitude and the more compressed the

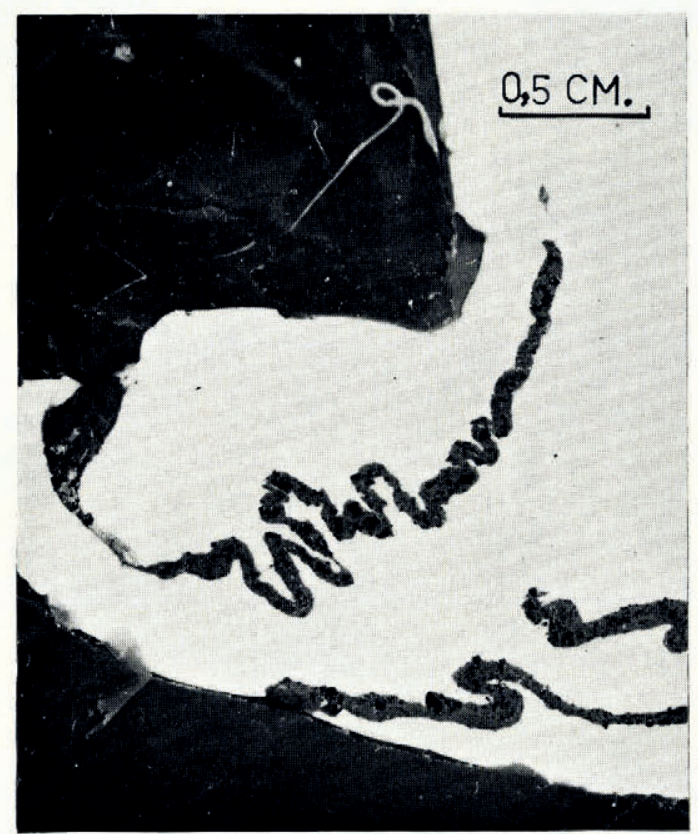

Fig. 7. Rather competent powdered-wax moraines buckled in a centrifuged model of a piedmont glacier of bouncing putty. Note the the rounded shape of folds even when strongly compressed

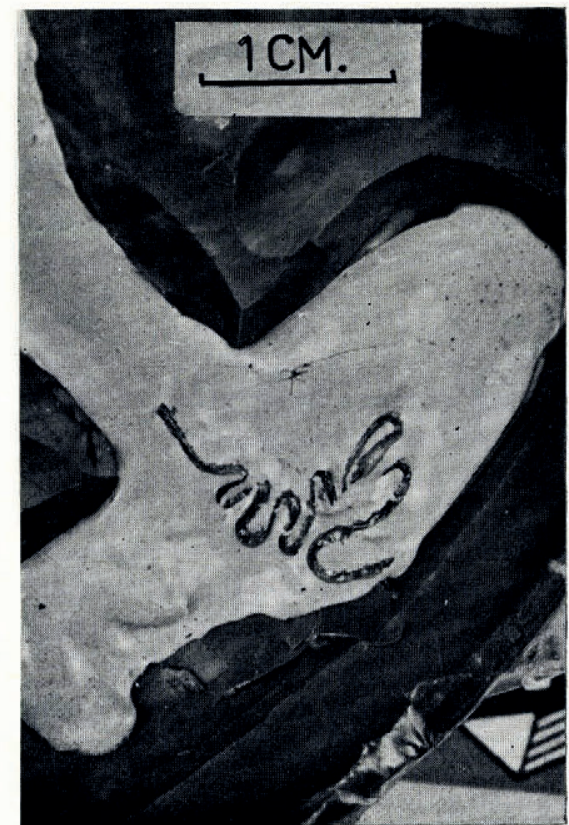

Fig. 8. Laver of competent stitching wax buckled in a centrifuged model of a piedmont glacier of bouncing putty. The stitching wax is considerably more viscous and stiff than any of the enclosed layers in the other models. Note in this connection the smooth rounded outline of the folds 


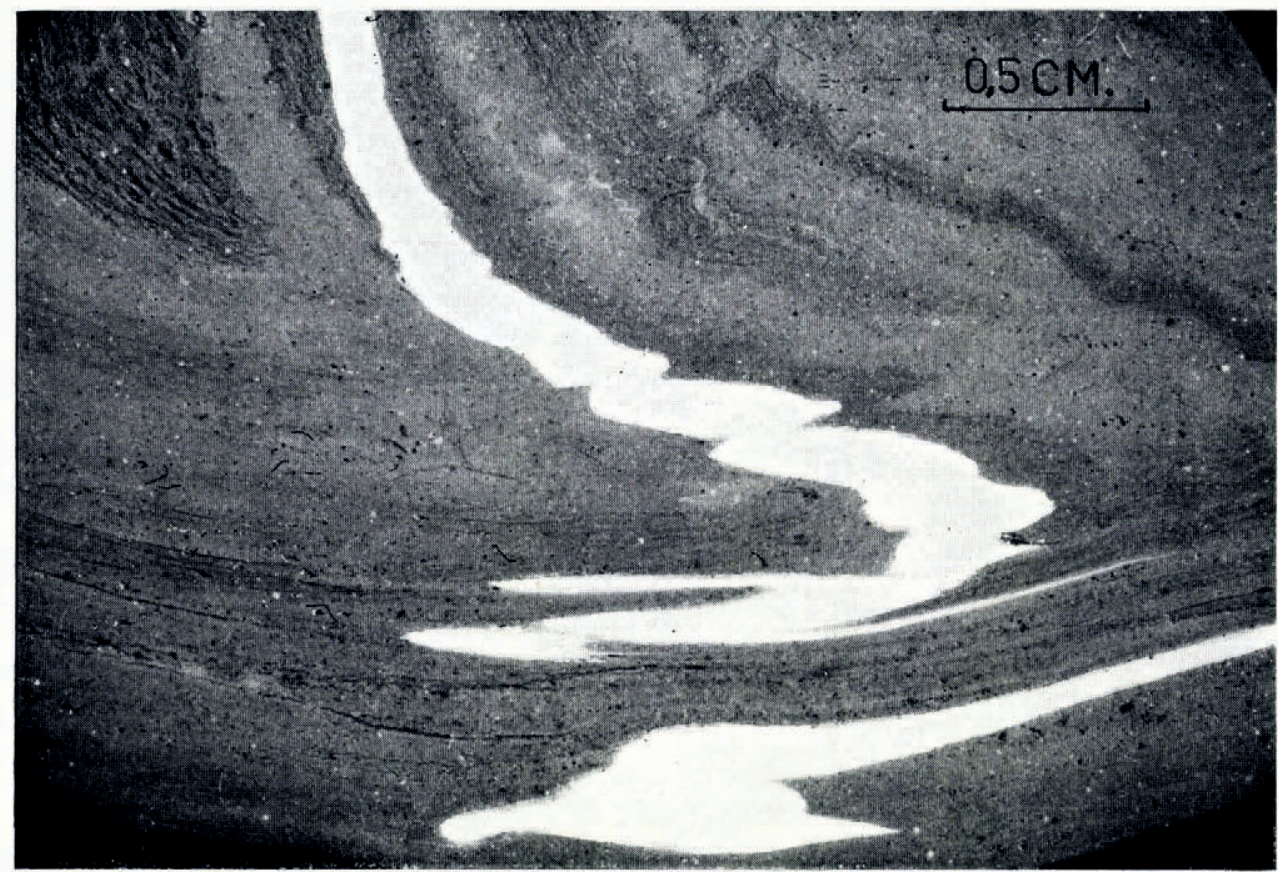

Fig. 9. Detail of part of a centrifuged piedmont-glacier model of heterogeneous bouncing putty. Compare this structure with the Malaspina Glacier structure in Figure $I I$

wave-length of the folds (see Fig. 13). This kind of accentuation of early folds and curved structures in general by later strain is very important in the models. The process must also be an important one in natural piedmont glaciers such as the Malaspina Glacier. As the buckled or bent moraines move towards the peripheral parts of the piedmont sheet, extension strain parallel to the periphery and compressive strain in a radial direction increase, as may be shown by the deformed neutral marker layers in the model of Figure 3. Growth of amplitude and shortening of wave-length of the early formed curves consequently occur as they move out towards the periphery of the piedmont lobe (Figs. 2 and 5).

In addition to the accentuation of early formed bends in the moraine, non-affine flow in the ice sheet generates long wave-length and often large-amplitude folds in the moraines as they move towards the periphery of the lobe (cf. Fig. 4). In the models these larger folds due to heterogeneous flow are at least partly caused by the irregularly varying slope of the substratum. It is also possible that such larger folds are produced by buckling of the whole multilayer of moraines, because the characteristic wave-length of densely spaced multilayers is larger than the wave-length of individual layers (Ramberg, I963[b]).

It is interesting to note how the accentuation of the folds caused by increasing homogeneous strain results in different fold styles in layers of different competency. Enclosed layers of materials whose viscosity does not differ sensibly from that of the surrounding material are strained at the same rate and to the same degree as the surrounding material. The shape of the final folds of such layers can therefore be readily constructed geometrically, based upon knowledge only of the amount of final strain in the neighbourhood and the shape of the original curved layer, such as shown in Figure I3. Layers which are more competent than the enclosing medium yield less readily than the surrounding substance. The strain is therefore non-affine in the neighbourhood of such layers. In particular, the component of compressive strain normal to the axial plane in the buckled layer itself, as well as in the contact zone adjacent to the layer, is less than in the region outside the contact zone (which is about one wave-length thick). 


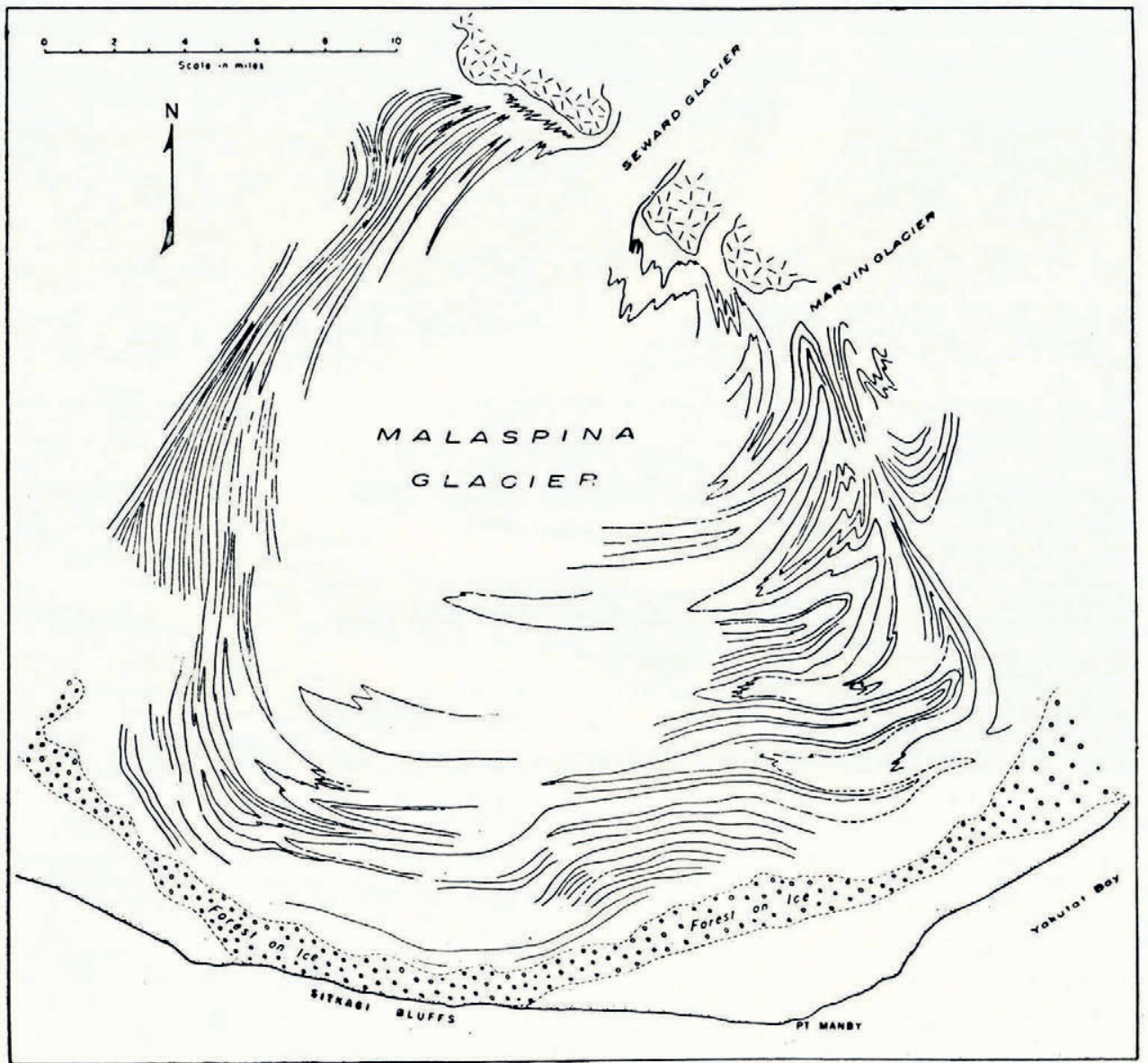

Fig. 1o. Fold pattern in Malaspina Glacier constructed from air-photograph mosaic (Sharp, 1958)

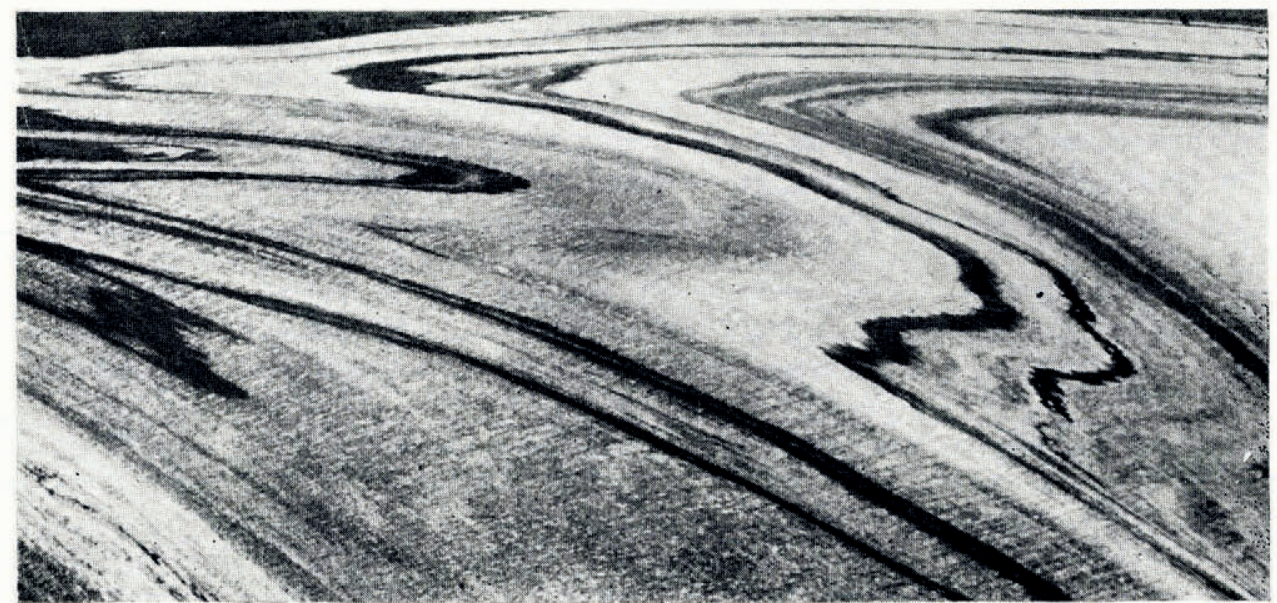

Fig. II. Photograph of folded moraines and debris bands in the Malaspina Glacier (Sharp, 1958) 


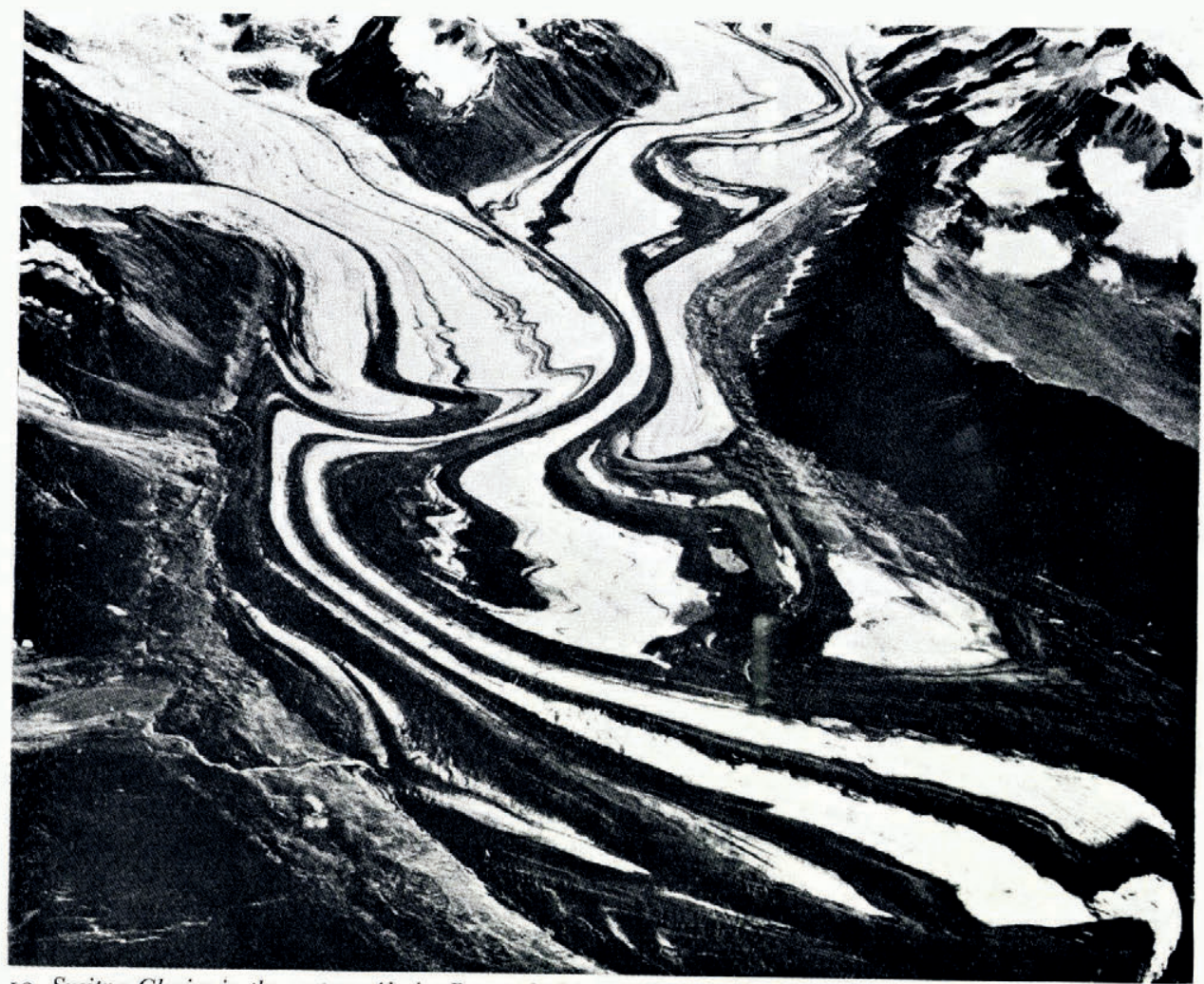

Fig. I2. Susitna Glacier in the eastern Alaska Range, looking north-east. Note buckling of the medial moraines where the ice tongues seem to meet resistance (Sharp, 1943)

In view of this discussion, consider the model shown in Figure 5. The spotted grey layer in the white bouncing putty glacier is wax-charged morainic material that is somewhat more rigid and/or more viscous than the pure bouncing putty. The uniformly shaded layer is brick-coloured bouncing putty with a viscosity not significantly different from that of the main body of bouncing putty. The pattern shown in the model is explained as follows: upon entering the piedmont flat the moraine-carrying glacier enters a new strain field with maximum compressive strain parallel to the moraine band (see above). The relatively competent moraine band therefore starts to buckle but the buckles are somewhat irregular, because of the uneven thickness and uneven grain-size of the admixed wax powder. Now, the strain in the contact zone along the moraine reflects the buckles as well as the variable thickness of the competent moraine. The rheologically neutral strip of coloured bouncing putty lies within this zone of contact strain. The strip of coloured putty consequently mimics passively the sinuous contact strain. As the material spreads out on the piedmont flat the early formed folds become accentuated but in different manners, because the two enclosed strips have different competencies. The competent moraine retains the rounded fold shape to a greater degree than the softer coloured bouncing putty strip which develops angular so-called chevron type folds. (Compare also Figures 6, 7 and 8.)

It is interesting that the angular sharp-pointed folds in the coloured strip are not due to shearing or slip along planes parallel to the axial planes as is sometimes assumed for similar styles of folds in natural glaciers (e.g. Sharp, I958, p. 636). Indeed, it is simply the change of geometric shape of the originally curved pattern under additional homogeneous strain (as demonstrated in Figure $\mathrm{I}_{3}$ ). 

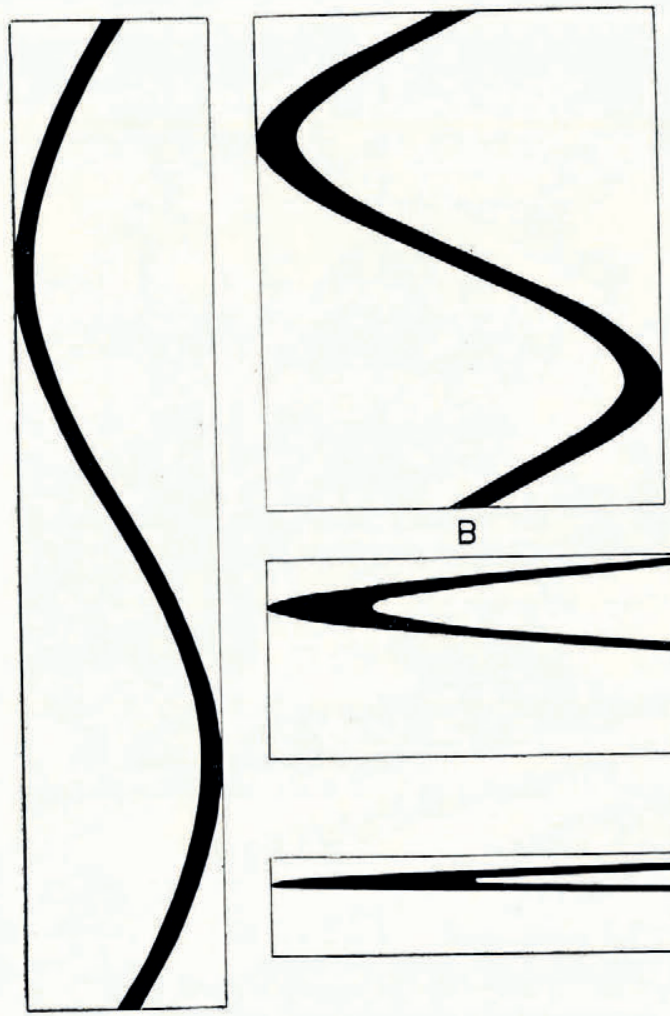

B

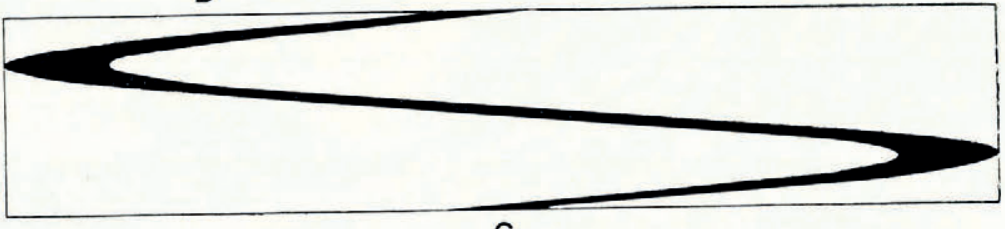

C

A

Fig. I3. An originally curved marker strip $(A)$ being exposed to homogeneous plane strain at constant volume. B shows 50 per cent shortening in a vertical direction and $C 80$ per cent. The change in shape of the black marker strip is solely due to the homogeneous strain without shear along the axial plane. $D$ shows $9^{\circ}$ per cent shortening (only half a wave is shown)

In concluding this note the writer wishes to emphasize the potentialities of the centrifuge technique in the laboratory study of a great number of glacier structures not mentioned here. For example, a detailed study of the strain geometry in three dimensions throughout a model glacier offers no difficulty, because the relative strength of the ice-imitation material permits study of sections through the model glacier at any time during its evolution. The strain distribution thus determined in a model glacier may then be compared with the attitude of layering or schistosity and elongation in a natural glacier. The controversy of the relation between these planar or linear structures and the strain ellipsoid may therefore be solved for individual cases. (The writer is working on this problem in schists and gneisses.) By mixing together the proper materials, it also seems possible to find a model material which is able to flow and fracture simultaneously under a centrifugal force of proper strength. Models made of such an imitation material will give interesting information on the evolution of fractures in glaciers.

MS. received 21 May 1963

\section{REFERENCES}

Biot, M. A. 1961. Theory of folding of stratified viscoelastic media and its implication in tectonics and orogenesis. Geological Society of America. Bulletin, Vol. 72, No. I 1, p. 1595-1620.

Ramberg, H. I963[a]. Experimental study of gravity tectonics by means of centrifuged models. Bulletin of the Geological Institution of the University of Upsala, Vol. 42 , No. I, p. I-97.

Ramberg, H. I $963[\mathrm{~b}]$. Fluid dynamics of viscous buckling applicable to folding of layered rocks. Bulletin of the American Association of Petroleum Geologists, Vol. 47, No. 3, p. 484-505.

Sharp, R. P. 1948. The constitution of valley glaciers. Journal of Glaciology, Vol. I, No. 4, p. 182-89.

Sharp, R. P. I958. Malaspina Glacier, Alaska. Bulletin of the Geological Society of America, Vol. 69, No. 6, p. 61 7-46. 